\title{
The Complaint Speech Act Set Produced by University Students Speaking English as a Foreign Language
}

\author{
Tanju Deveci \\ The College of Arts and Sciences \\ The Petroleum Institute \\ Abu Dhabi, UAE
}

\begin{abstract}
Dissatisfied with their marks for assignments, some university students may visit their professors to make a complaint. However, the speech act of complaint, as an aspect of pragmatic competence, has not received as much attention as other speech acts from researchers. The face-threatening nature of this speech act requires special attention in multicultural contexts, an example of which is the United Arab Emirates. A large majority of the teaching staff in the UAE comes from other cultures; and therefore, an investigation into this speech act has the potential to improve communication between students and faculty. This research investigated freshman English students' realization of the complaint speech act set. Data were collected from 89 students with a mean age of 19, using a role-play situation. Also, a judgment scale was completed by two instructors to assess the effectiveness of students' performance. The findings reveal that the students have difficulty presenting their case, thus, producing the speech act of criticism along with complaint. They also produce both requests and demands as possible solutions. The judgment scales reveal that the students' attitudes are not generally appropriate. Thus, it has been concluded that explicit instruction about speech acts in general, and complaint in particular, would improve interpersonal communication in multicultural societies.
\end{abstract}

\section{Introduction}

Communication with others requires shared symbols. Parties' shared linguistic background provides a set of symbols, enabling communication. Linguistic competence, therefore, is at the heart of successful communication, and it can be context free to a certain extent. However, a linguistically appropriate message lacking social appropriateness will likely cause a communication breakdown. This feature of effective communication was highlighted back in 1972 by Hymes who asserted that effective communication requires speakers to know how members of ther speech community use language in order to accomplish their communication purposes. A voluminous literature has been devoted to Hymes' assertion, influencing approaches to teaching foreign languages in general, and English in particular. This has led to the two foreign language teaching approaches proposed by Canale and Swain [9]: the grammatical and communicative approaches. The former refers to grammatical/linguistic forms such as phonological forms, morphological forms, and lexical items, as well as how they are organized to form sentences that are grammatically correct. The latter, on the other hand, is based on communicative functions emphasizing how grammatical forms are used for certain functions in appropriate ways, which embody speech acts.

\section{Speech Acts}

Austin [4] states that uttering a sentence means performing an action. In other words, saying something is doing something or performing an act. He identifies three kinds of acts:

(i) locutionary act: the utterance of a sentence with determinate sense and reference.

(ii) illocutionary force (act): the making of a statement, offer, promise, etc. in uttering a sentence, by virtue of the conventional force associated with it. (iii) perlocutionary act: the bringing about of effects on the audience by means of uttering the sentence, such effects being special to the circumstances of utterance.

Illocutionary force has also come to be known as 'Speech Acts.' Speaking a language means performing speech acts that serve to perform communicative functions such as offering, thanking, criticizing and complaining [28]. First introduced by Austin [4] in his book How to Do Things with Words, the notion of speech acts is based on the distinction between 'constative utterances' and 'performative utterances'. The former refers to utterances that can be evaluated along a dimension of truth when uttered. On the other hand, the latter is utterances in which something is done, and such utterances cannot be true or false. However, they can go wrong and become 'unhappy'. To avoid this, certain 'felicity conditions' need to be met:

A.(i) There must exist an accepted conventional procedure having a certain conventional effect 
(ii) The particular persons and circumstances in a given case must be appropriate

B. The procedure must be executed by all participants

(i) correctly and

(ii) completely

C. (i) Where, as often, the procedure is designed for use of persons having certain thoughts or feelings, or for the inauguration of certain consequential conduct on the part of any participant, then a person participating in and so invoking the procedure must in fact have those thoughts and feelings, and the participant must intend so to conduct themselves, and

(ii) must actually so conduct themselves subsequently [4].

Violations of $\mathrm{A}$ and $\mathrm{B}$ conditions bring about 'misfires' [18]; that is, the intended actions fail to come off. Violations of C conditions, called 'abuses,' can be difficult to detect at the time of the utterance, but can result in an action performed infelicitously or insincerely. The same utterance can have different illocutionary forces. The intended force, felicity conditions and Illocutionary Force Indicating Devices (IFID) can help identify the intended meaning [35]. Speakers of a foreign language may make negative pragmatic transfer if they mistakenly generalize pragmatic knowledge of their native tongue (L1) to the language they are learning (L2) [36]. They may also form their own rules with an end product that might not entirely fit in L2 and suffer from flaws. This 'in-between language,' known as 'interlanguage,' can be independent of both L1 and L2 [12]. Kasper points out that an illocutionary act and politeness values are key elements of pragmalinguistic transfer [17].

\subsection{Complaint as a Speech Act}

The speaker (S) performs the speech act of complaint to "expresses displeasure or annoyance censure- as a reaction to a past or going action, the consequences of which are perceived by $\mathrm{S}$ as affecting her unfavorably" [24]. The following preconditions exists for a speech act to be considered as a complaint:

Hearer $(\mathrm{H})$ performs a socially unacceptable act (SUA) that is contrary to a social code of behavioral norms shared by $\mathrm{S}$ and $\mathrm{H}$.

(1) S perceives the SUA as having unfavorable consequences of herself, and/or for the general public.

(2) The verbal expression of $S$ relates post facto directly or indirectly to the SUA, thus having the illocutionary force of censure.

(3) S perceives the SUA as: (a) freeing S (at least partially) from the implicit understanding of a social commiserating relationship with $\mathrm{H} ; \mathrm{S}$ therefore chooses to express her frustration or annoyance...; and (b) giving $\mathrm{S}$ the legitimate right to ask for repair in order to undo the SUA, either for her benefit or for the public benefit. It is the latter perception that leads to instrumental complaint aimed at "changing thing" that do not meet with our standards or expectations. The main goal of such instrumental complaint is to ensure that $\mathrm{H}$ performs some action of repair as a result of the complaint [24].

A complaint helps $\mathrm{S}$ to express displeasure or annoyance, and to hold the hearer $(\mathrm{H})$ accountable for the action causing this, confront a problem with the intention of improving the situation, and possibly to suggest or request a correction, to obtain agreement, and to establish a common bond between the speaker and addressee, helping him/her to open and/or sustain conversations [6], [8], [24]. Four components exist in the complaint speech act set produced by Americans: the explanation of purpose / warning of the forthcoming complaint, the complaint itself, the justification, and a candidate solution in the form of a request [23].

\subsection{Linguistic Characteristics of Complaints}

The linguistic features of complaints produced by American speakers are as follows [23]:

- Use of the pronoun 'we' to indicate that both parties share the blame, and as a way of negotiating the problem

- Use of questioning to ask for advice, for permission to explain oneself, and to get the listener to reconsider or discuss the problem

- Depersonalization of the problem to transfer blame from the interlocutor to the problem

- Use of mitigators to soften the complaint (e.g., kind of, perhaps, somehow)

- Acceptance of partial responsibility for the problem.

\subsection{Criticism vs. Complaint}

The criticism speech act differs from a complaint since the speaker produces much more blunt, contemptuous, and direct utterances (Sauer, 2000) and holds the hearer responsible for the problem faced. This may change the course of a dialogue drastically. One needs to consider the social status of the hearer when deciding whether or not to issue a criticism, since an inappropriate move may have severe consequences. The criticism speech act may contain the following characteristics [23]:

(a) Use of second person + modal 'should' that indicates that the speaker is in a position to dictate the behaviour of the listener.

(b) Personalization of the problem, placing the blame on the hearer. 
(c) Refusal to accept responsibility for the problem.

\subsection{Previous Research on Complaints}

Research on the complaint speech act has often considered the power-relationship between $\mathrm{S}$ and $\mathrm{H}$. For instance, Akinci investigated how the severity of a complaint was affected by the degree of formality between the $\mathrm{H}$ and $\mathrm{S}$ [1]. Interestingly, female respondents were found not to use any politeness strategies when complaining. The change in complainers' strategy use according to the power relationship between $\mathrm{S}$ and $\mathrm{H}$ has also been echoed in research in Indonesia [13]. It was revealed that the respondents changed their degree of politeness by opting for indirect accusation when the complainee has a higher status. Deveci [11] also investigated university students' use of the complaint speech act with professors who were either commiserating or contradicting. In that study, students were found to produce the criticism speech act along with complaint. They were also found to employ 'demand' as a candidate solution. A request, however, appeared much more frequently when students conversed with a commiserating teacher as opposed to a contradicting teacher.

Among the limited research conducted with learners of Arabic origins is a study by Umar, who studied Sudanese graduate students' pragmatic competence with a view to complaints [31]. His research revealed that students produced fewer components of the complaint speech act set than usual. They were found to be overly confrontational in their complaints about a stranger cutting in line. However, they were also found to be too complacent when complaining to a close friend. In their quest for solutions to perceived problems, there were instances of inquiry and imperative use directed to $\mathrm{H}$ of a higher status. Taken together, these are regarded as inefficiencies and a lack of pragmatic competence in students' L2 use, which in turn causes failures in the required felicity conditions [4], [31]. In previous research, Sudanese students' failures have been attributed to linguistic limitations as well as cultural differences [31]. On the other hand, Iranian learners of English as a foreign language have been identified using more criticism in comparison to native English speakers by expressing their dissatisfaction more explicitly [29].

Another study on language learners' use of the complaint speech act was carried out in the Iraqi context by Mayouf [21]. Students were found to produce criticism as well as complaint. In addition, they used demand as a candidate solution, which deviated from data from native speakers of English. It is concluded that Iraqi Arabic speakers might be expected to be more polite and avoid criticism when engaged in face-to-face communication with someone of higher status like their course instructors.
Hussein and Al-Mofti (2014) also identified impairments in Iraqi language learners' use of the complaint speech act. These were mainly caused by linguistic problems. The respondents lacked competence in using expressions of complaint with people of higher status. Cross-cultural differences also accounted for impairments when they were asked to make a complaint to people more powerful than themselves. Both limited linguistic competence and cultural differences were identified as factors that contributed to the reduced levels of sociolinguistic appropriateness in complaints produced by Iranian speakers of English (Azarmi \& Behnam, 2012).

\section{Researcher's Context and Rationale for the Study}

The current research was conducted at The Petroleum Institute (PI) in Abu Dhabi, the UAE. PI offers undergraduate degrees in Chemical Engineering, Mechanical Engineering, Materials Science and Engineering, Petroleum Engineering and Petroleum Geosciences. As a support program to the engineering departments, the College of Arts and Sciences (CAS) houses various departments including the Communication Department, which aims at furnishing students with the skills required to be successful communicators as future engineers through its communication courses (COMM101 and COMM151).

The teaching philosophy at PI requires the faculty to have an open-door policy with the intention of encouraging students to interact with them. This helps students share their feelings and thoughts with their instructors more easily. Coupled with their desire to achieve academic success (partly because of their fear of losing their monthly payments), quite a few students seem to rush to their instructors' offices to discuss grades awarded for assignments. This is generally welcomed since it is regarded as an opportunity to promote greater development. However, anecdotal evidence shows that not many students meet the felicity conditions for their performative utterance to become 'happy.' This may be mainly fueled by their lack of pragmalinguistic and sociopragmatic competence, which are particularly important in the realization of the facethreatening speech act of complaints. Although I acknowledge Zegarac and Pennington's argument that negative transfer from mother tongue L1 to L2 and/or the new forms of interlanguage do not necessarily lead to communicative failure, students' lack of pragmatic competence creates a certain level of uneasiness in their instructors, potentially resulting in frustration when the visits are regular [36]. However, the apparent lack of empirical data on Arab English speakers' use of complaints in general limits the understanding of the challenges 
facing students and faculty. The problem is intensified in the case of Emirati speakers of English as a foreign language due to the absence of previous research into this speech act, which provided the impetus for this study. Data from this research, therefore, are hoped to shed light on pragmatic choices made by students expressing their dissatisfaction to someone of higher status, their instructors. The results regarding sociolinguistic tendencies and failures may inform instructional designs in educational contexts.

With the above-mentioned rationale, this study aims at answering the following questions:

1. Given the context of expressing dissatisfaction with a grade earned on an assignment, do Communication students at The Petroleum Institute (PI) produce the complaint speech act in English? What are the components of the complaint speech act set produced?

2. Do their realizations of the complaint speech act differ according to gender and course (COMM101 vs. COMM151)?

3. What are the linguistic features of the complaint speech act produced by students?

4. How do instructors in the Communication Department judge the students' production of the complaint speech act set?

\section{Methodology}

\subsection{Subjects}

a) Students: A total of 89 freshman students participated in this study. $41(46 \%)$ of these students were male, and 48 of them (54\%) were female. 38 (43\%) were COMM 101 students and 51 (57\%) were COMM 151 students. Their ages ranged between 17 and 22, with a mean age of 19. All of the participating students were of Arab origins, with 89.5\% Emirati. There were also students from Jordan $(4.6 \%)$, Libya (3.5\%), Tunisia (1.2\%), and Yemen $(1.2 \%)$.

Most of the students (83\%) had taken the Test of English as a Foreign Language (TOEFL) in order to be eligible for their freshman studies. 15 of them (27\%), however, had taken the International English Language Testing System (IELTS). Most of the students in the second group were female $(80 \%)$. For ease of data analysis, IELTS scores were converted into a TOEFL result. The students' average TOEFL score was 541.25, with a range between 500 and 650 . The female students' average TOEFL score was higher than that of the male students (553 vs. 529.5).

b) Interlocutors: One instructor from the Communication Department participated in the study as the interlocutor. c) Judges: In order to determine whether or not the student participants achieved their communication aims, two instructors in the Communication Department participated as judges.

\subsection{Instruments and Analyses}

a) The Role-play: The speech act data were collected via a set of role-play tasks: one for the students and one for the interlocutors. A role-play was chosen as a data-gathering instrument since it allows for more authentic situations with respondents having control over the direction of the conversations [27]. In order to reduce the anxiety the respondents might feel, extra care was taken to ensure that the situation in the role-play was as realistic as possible [32]. All the participants remarked that the role-play was very familiar to them and that they often engaged in the given situation. However, three students stated that they normally avoided putting their case when faced with such situations. Data from these students were excluded in the study in order not to force unnatural behavior and prevent problematic results if the students were not good actors [10].

All role-plays were audio recorded for conversation analysis. After the transcription of the recordings, the encoding was conducted separately by two researchers separately according to Murphy and Neu's complaint strategy categories for complaints. Later, they exchanged encodings to determine if there were any discrepancies between the two sets [23]. Any cases of discrepancies were resolved in a forum.

Comparisons were made between genders and the two Communication courses (COMM 101 vs. COMM 151). For this purpose, descriptive statistics such as frequencies and percentages were used to describe the components of the complaint speech act set, along with the criticism speech act. A paired sample t-test was conducted to identify any differences between the data sets at a statistically significant level. A p-value of .05 was considered to indicate a statistical significance.

b) The Linguistic Features Set: The linguistic features of complaints produced by the participants were analyzed by two researchers separately according to the categories identified by Murphy and Neu [23]. Their analyses were crosschecked by a third researcher to identify any discrepancies, which were resolved in a forum held with these three researchers.

c) The Acceptability Judgment Questionnaire: In order to determine if the students achieved their communication aims, an adapted version of Murphy and Neu's acceptability judgment questionnaire was used [23]. The Acceptability Judgment Questionnaire was filled in by two judges, both of whom were Communication Department instructors. 
They listened to the data sets separately and evaluated the students' utterances according to six factors: aggressiveness, respectfulness, credibility, appropriateness, and differences in their approach to the situation. They rated each of these features indicating agreement, disagreement or uncertainty (maybe). Cohen's Kappa $(\kappa)$ was used to assess the agreement between the judges.

\section{Results}

The first research question aimed at identifying whether or not the Communication students at PI produced the complaint speech act when expressing disagreement to their instructors. It also aimed at identifying components of this speech act. The results of data analysis regarding this question can be seen in Table 1.

Table 1. The speech act of complaint and its components produced by participants

\begin{tabular}{|c|c|c|c|c|}
\hline \multicolumn{2}{|c|}{ Components } & $\begin{array}{l}\text { Total } \\
N=89\end{array}$ & $\begin{array}{l}\text { Frequency } \\
\text { of use }(\%)\end{array}$ & Sample Responses \\
\hline \multicolumn{2}{|c|}{$\begin{array}{l}\text { Explanation of } \\
\text { Purpose }\end{array}$} & 72 & 80.90 & $\begin{array}{l}\text { I want to discuss with you the grade } \\
\text { that you gave at the assignment. }\end{array}$ \\
\hline \multicolumn{2}{|c|}{ Complaint } & 59 & 66.30 & $\begin{array}{l}\text { Sir, I'm not really happy with my } \\
\text { grade actually. }\end{array}$ \\
\hline \multicolumn{2}{|l|}{ Criticism } & 40 & 45 & $\begin{array}{l}\text { You didn't give me enough } \\
\text { information so I can improve myself. }\end{array}$ \\
\hline \multicolumn{2}{|c|}{ Justification } & 80 & 89.90 & $\begin{array}{l}\text { Because I think I worked enough to get } \\
\text { a high grade. }\end{array}$ \\
\hline \multirow[b]{2}{*}{ Solution } & Request & 57 & 64 & If possible, can I repeat it? \\
\hline & Demand & 29 & 32.60 & $\begin{array}{l}\text { I want you to explain me why you give } \\
\text { me this grade. }\end{array}$ \\
\hline
\end{tabular}

As can be seen in Table 1, 66.30\% of the students produced the complaint speech act. Their complaints showed their perception of being unfairly treated by the teacher. The topic of their complaints generally concerned their grade as in the example below:

(a) I got a really bad grade.

Criticism, which occurred in $45 \%$ of the students' utterances, was used less frequently than complaint. The topic of their criticism focused on the teacher awarding the grade, as shown in the sample

(b) and (c):

(b) You give me a low grade for my assignment.

(c) That's why you give me this low grade.

It is also important to note that not every student produced all the components of the complaint speech act set. That is, approximately $20 \%$ of the students failed to explain the reason for their visit. When they did provide the purpose for their visit, they often focused on the assignment. A sample utterance is seen in (d):

(d) I just want to talk to you about the assignment we did earlier.

Regarding justification, about $11 \%$ of the students avoided providing a justification for their case. Those who did provide a justification, however, generally chose to mention the amount of time they spent on the assignment and the perceived quality of their papers. Some examples are as follows:

(e) I already spent a lot of time in this assignment, I spent a week, I didn't sleep well.

(f) I went to the ILC [Independent Learning Center], I worked on it, I went to the support center and did what I have to do.

The instructions for the role-play had included a difference in the students' and the teacher's beliefs as one of the potential justifications for the grade perceived as unfair by the students. Further analysis was conducted to detect if it appeared in the students' utterances. Only 15 students (16.9\%) used it in their justifications, as illustrated in (j) and (k):

(g) I think my content is different from your belief.

(h) I think you have different belief.

Another important result is related to candidate solutions. $64 \%$ of the students chose to use the request speech act as a solution. These students asked the instructors to reconsider their marks and give them a chance to improve their papers. Some of the sentences uttered by the students to request a solution are:

(i) May you see my assignment again and see if you can give me another feedback?

(j) Can you give me a second chance to prove myself and do it again?

On the other hand, 29 instances of demand as a candidate solution $(32.60 \%)$ were detected in the students' utterances. These students demanded an explanation for their low marks and a change to their grade as in the sample utterance below:

(k) I want to know the reason sir, why I got this bad grade.

Some candidates $(7.9 \%)$, on the other hand, avoided requesting or demanding a solution.

Analyses were also conducted to determine the order in which the students used the components of the complaint speech act set. The results of data analysis regarding this can be seen in Table 2 .

Table 2. The order of components

\begin{tabular}{|l|c|c|c|c|c|c|c|c|c|c|}
\hline \multirow{2}{*}{ Moves } & \multicolumn{8}{|c|}{ Components of Complaint Speech Act Set* } \\
\cline { 2 - 12 } & $\begin{array}{c}\text { Explanation } \\
\text { of Purpose }\end{array}$ & \multicolumn{2}{|c|}{ Complaint } & \multicolumn{2}{c|}{ Criticism } & \multicolumn{2}{|c|}{ Justification } & \multicolumn{2}{|c|}{ Solution } \\
\cline { 2 - 12 } & $\mathrm{f}$ & $\%$ & $\mathrm{f}$ & $\%$ & $\mathrm{f}$ & $\%$ & $\mathrm{f}$ & $\%$ & $\mathrm{f}$ & $\%$ \\
\hline Move 1 & 70 & 78.65 & 12 & 13.48 & 3 & 3.37 & 2 & 2.25 & 2 & 2.25 \\
\hline Move 2 & 2 & 2.25 & 44 & 49.44 & 19 & 21.35 & 21 & 23.60 & 4 & 4.49 \\
\hline Move 3 & 1 & 1.12 & 3 & 3.37 & 11 & 12.36 & 47 & 52.81 & 21 & 23.60 \\
\hline Move 4 & 0 & 0 & 0 & 0 & 4 & 4.49 & 9 & 10.11 & 44 & 49.44 \\
\hline
\end{tabular}

Frequencies are based on number of times the components occurred in student responses, rather than total number of students.

Table 2 indicates a general trend for the order of moves. That is, an explanation of purpose was the most frequently occurring move at the beginning of the conversations. Having explained why they came 
to visit their instructor, the students moved to the second stage where they expressed their dissatisfaction with their grade by either complaining or criticizing. This was followed by the third move helping them to justify their case. The sequence of moves was completed by the fourth stage where the students produced a solution to the perceived problem. Overall, this order seems reasonable. However, there were certain deviations, the most important of which is regarding the first move where a complaint appeared twelve times $(13.48 \%)$ in student utterances. Criticism was also produced during the first stage by three students $(3.37 \%)$. Taken together, complaint and criticism appear in $16.85 \%$ of the student responses at the very first stage. Although minimal in number, two students $(2.25 \%)$ started with a justification while two other students $(2.25 \%)$ provided a solution to the situation regarded unfair.

It is also important to note that the second stage, where students generally complained and/or criticized, hosts a number of utterances stating a justification $(23.60 \%)$. That is, some students first explain how hard they studied and/or how good their papers actually are before they express their dissatisfaction with the grade awarded. This appears to create some confusion on the part of the instructor, as in the example below.

(1) Student: Sir, I want to discuss my assignment.

Teacher: OK

Student: I feel that I did good in it. I worked so hard on it.

Teacher: That's good.

Student: But sir I took it to the Writing Center too.

Teacher: Right.

Student: Sir can you help me?

Teacher: Help? you say you did a good job with your assignment?

The second research question aimed at determining differences between the data sets according to gender and courses taken. The results of data analysis according to gender can be seen in Table 3 .

Table 3. Comparison between male and female students' use of complaint speech act

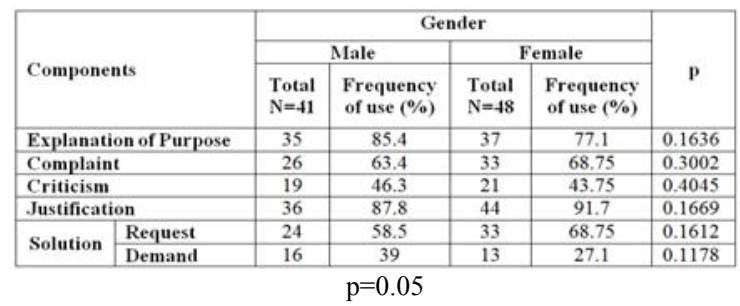

Table 3 shows that the female students generally produced the components of the speech act set more often than their male counterparts. For example, a complaint was detected more often in their utterances $(68.75 \%$ vs. $63.4 \%)$. Similarly, a justification occurred in more of the female utterances than it did in the male utterances $(91.7 \%$ vs. $87.8 \%)$. It is also important to note that a request appeared in $68.75 \%$ of the utterances by the female students, while it appeared in $58.5 \%$ of the utterances by the male students. Despite this, only $77.1 \%$ of the female students provided an explanation of purpose compared to $85.4 \%$ of the male students. On the other hand, a criticism was produced by male students more frequently $(46.3 \%$ vs. $43.75 \%)$. Similarly, demand was uttered by more male students $(39 \%$ vs. $27.1 \%)$. Taken together, the female students seem to be more successful in producing the components of the complaint speech act set although the analysis conducted to determine statistically significant differences between the male and female data sets revealed no difference regarding any of the components.

The results of data analysis according to course variable can be seen in Table 4.

Table 4. COMM101 and COMM151 students' use of complaint speech act

\begin{tabular}{|c|c|c|c|c|c|c|}
\hline \multirow{3}{*}{\multicolumn{2}{|c|}{ Components }} & \multicolumn{4}{|c|}{ Courses } & \multirow[b]{3}{*}{ P } \\
\hline & & \multicolumn{2}{|c|}{ COMIMI01 } & \multicolumn{2}{|c|}{ COMM151 } & \\
\hline & & $\begin{array}{l}\text { Total } \\
N=38\end{array}$ & $\begin{array}{l}\text { Frequency } \\
\text { of use }(\%)\end{array}$ & $\begin{array}{l}\text { Total } \\
N=51\end{array}$ & $\begin{array}{l}\text { Frequency } \\
\text { of use }(\%)\end{array}$ & \\
\hline \multicolumn{2}{|c|}{$\begin{array}{l}\text { Explanation of } \\
\text { Purpose }\end{array}$} & 28 & 73.7 & 44 & 86.3 & 0.0690 \\
\hline \multicolumn{2}{|c|}{ Complaint } & 29 & 76.3 & 30 & 58.8 & 0.043 \\
\hline \multicolumn{2}{|c|}{ Criticism } & 19 & 50 & 21 & 41.2 & 0.2067 \\
\hline \multicolumn{2}{|c|}{ Justification } & 34 & 86.5 & 46 & 90.2 & 0.3329 \\
\hline \multirow{2}{*}{ Solution } & Request & 25 & 73.5 & 32 & 62.7 & 0.3851 \\
\hline & Demand & 14 & 36.8 & 15 & 29.4 & 0.2325 \\
\hline
\end{tabular}

It is seen in Table 4 that COMM101 students generally produced the components of the complaint speech act set more often than COMM151 students. The most striking difference was regarding the complaint component. COMM101 students produced a complaint much more often than COMM151 students $(76.3 \%$ vs. $58.8 \%)$, which was found to be significant at a statistically significant level $(p=0.043<0.05)$. However, they were also found to issue a criticism more often than COMM151 students (50\% vs. $41.2 \%$ ), although there was not a statistically significant difference between the two data sets $(p=0.2067>0.05)$. COMM101 students also resorted to both a request and a demand more often than COMM151 students $(73.5 \%$ vs. $62.7 \% ; 36.8 \%$ vs. $29.4 \%$ respectively), despite a lack of statistically significant difference between the data sets $(p=0.385169>0.05$ and $p=0.232556>0.05)$. On the other hand, an explanation of purpose and justification occurred in COMM151 students' responses more often than they did in COMM101 students $(86.3 \%$ vs. $73.7 ; \quad 90.2 \%$ vs. $86.5 \%$ respectively). Still, no statistically significant difference between these data sets were detected 
$(\mathrm{p}=0.06906>0.05 \quad$ and $\quad \mathrm{p}=0.332943>0.05$ respectively).

The third research question aimed at identifying the linguistic features of the complaint speech act set produced by the participants of the study. Table 5 below presents the frequency of each feature in the students' responses.

Table 5. Linguistic features of the complaint speech act set produced by participants

\begin{tabular}{|c|c|c|c|c|c|c|}
\hline \multirow{3}{*}{$\begin{array}{l}\text { Linguistic } \\
\text { Features }\end{array}$} & \multicolumn{3}{|c|}{ Gender } & \multicolumn{3}{|c|}{ Class } \\
\hline & Male & Female & Total & COMM101 & COMM1151 & Total \\
\hline & & & $\mathrm{f}$ & & f & $\mathrm{f}$ \\
\hline Use of mitigators & 46 & 54 & 100 & 64 & 36 & 100 \\
\hline $\begin{array}{l}\text { Use of } \\
\text { questioning }\end{array}$ & 29 & 22 & 51 & 20 & 31 & 51 \\
\hline $\begin{array}{l}\text { Depersonalization } \\
\text { of the problem }\end{array}$ & 17 & 15 & 32 & 17 & 15 & 32 \\
\hline $\begin{array}{l}\text { Use of pronoun } \\
\text { 'we' }\end{array}$ & 8 & 7 & 15 & 7 & 8 & 15 \\
\hline $\begin{array}{l}\text { Acceptance of } \\
\text { partial } \\
\text { responsibilities of } \\
\text { the problem }\end{array}$ & 8 & 5 & 13 & 7 & 6 & 13 \\
\hline Total & 108 & 103 & 211 & 115 & 96 & 211 \\
\hline
\end{tabular}

As can be seen in Table 5, the most frequently used linguistic feature was mitigators to soften complaints. One hundred instances of mitigators were detected in the data sets. Among these, 'just' (44\%) and 'maybe' (36\%) occurred most frequently. Other mitigators detected were 'a (little) bit' $(6 \%)$, 'kind of' (5\%), 'you know' (4\%), 'I mean' (4\%), and 'Don't you think?' (1\%). Examples include:

(m) I'm kind of not happy with my grade.

(n) I just regarding on the low grade that I have for the last assignment.

When the gender variable is considered, it is seen that mitigators were used more often by female students than by male students (54\% vs. $46 \%)$. Regarding the course variable, COMM101 students were found to utilize mitigators much more often than COMM151 students ( $64 \%$ vs. $36 \%$ ).

The second most frequently used linguistic feature was the use of questioning which was mainly utilized to get the instructor to reconsider the grade given. This feature emerged fifty-one times, as in the following example:

(o) Can you check it for me again please?

Some students, however, used this feature to seek advice to improve their future performance. For example, one student said:

(p) What can I do to increase my grade next time?

It is interesting to note that none of the students used a question to ask for permission to explain their case. This feature was used by male students more often than by female students ( $57 \%$ vs. $43 \%)$. Similarly, COMM151 students used it more often than COMM101 students (61\% vs. 39\%).

Another linguistic feature used by the participants was depersonalization of the problem, which occurred thirty-two times, serving to transfer blame from the instructor to the problem, an example of which is seen below:

(q) I don't believe I deserve this grade.
Both male and COMM101 students used this feature slightly more often than female and COMM151 students (53\% vs. $47 \%)$.

The personal pronoun 'we' was also used to negotiate the problem. However, this feature was used comparatively less frequently, occurring just fifteen times. Male and COMM151 students used it more than female and COMM101 students (53\% vs. $47 \%$ ). See the following example:

(r) If we can sit together to see the problems.

The least frequently occurring linguistic feature identified was the acceptance of partial responsibility for the problem, which emerged thirteen times in the data. A sample response is as follows:

(s) I think that maybe we can't understand each other.

Male students used this feature more regularly than female students $(62 \%$ vs. $38 \%)$. Similarly, COMM101 students' uses of this feature were more numerous than those of COMM151 students (54\% vs. $46 \%$ ).

The last research question aimed at identifying instructors' perceptions of students' complaint speech act production. For this purpose, two instructors in the Communication Department performed acceptability judgements. Table 6 displays their responses as well as the inter-rater reliability test conducted.

Table 6. Acceptability judgements

\begin{tabular}{|l|c|c|c|c|c|c|}
\hline \multirow{3}{*}{ The Feature } & \multicolumn{2}{|c|}{ Judge 1 } & \multicolumn{2}{c|}{ Judge 2 } & & \\
\cline { 2 - 6 } & $\begin{array}{c}\text { Yes \& } \\
\text { Maybe } \\
\mathbf{f} \%\end{array}$ & $\begin{array}{c}\text { No } \\
\mathbf{f} \%\end{array}$ & $\begin{array}{c}\text { Yes \& } \\
\text { Maybe } \\
\mathbf{f} \% \%\end{array}$ & $\begin{array}{c}\text { No } \\
\mathbf{f} ; \%\end{array}$ & $\begin{array}{c}\text { Inter-rater } \\
\text { Reliability }\end{array}$ & \multirow{2}{*}{$\mathbf{p}$} \\
\hline Pushiness & $46 ; 52$ & $43 ; 48$ & $58 ; 66$ & $31 ; 34$ & 0.30 & 0.001 \\
\hline Respectfulness & $64 ; 72$ & $25 ; 28$ & $53 ; 60$ & $36 ; 40$ & 0.26 & 0.001 \\
\hline Appropriateness & $53 ; 60$ & $36 ; 40$ & $29 ; 33$ & $60 ; 67$ & 0.16 & 0.018 \\
\hline Credibility & $3 ; 3$ & $86 ; 97$ & $20 ; 23$ & $69 ; 77$ & 0.41 & 0.472 \\
\hline Different Approach & $76 ; 85$ & $13 ; 15$ & $86 ; 97$ & $3 ; 3$ & 0.31 & 0.001 \\
\hline
\end{tabular}

As can be seen in Table 6, both judges found quite a few students pushy in their dialogue with the instructor $(52 \%$ and $66 \%)$. The judges also felt that certain students were not respectful to their instructor in their attempt to express their disappointment with their marks (28\% and $40 \%)$. Similarly, the judges were skeptical about a certain number of students' ability to talk about the situation appropriately. Although the second judge was more critical of this inability $(67 \%)$, the first also believed that $40 \%$ of the students faced a challenge in regard to this component. Taken together, the judges' responses suggest that the students' talk was not always appropriate.

The inter-rater reliability test conducted to assess the degree of agreement between the judges in terms of these three components did reveal that their responses were consistent at a statistically significant level $(\kappa=0.30, p=0.001 ; \kappa=0.26, p=0.001 ; \kappa=0.16$, $\mathrm{p}=0.018$ respectively). Although there was a 
moderate level of consistency between the judges' ratings of credibility $(\kappa=0.41)$, the statistical analysis did not reveal a consistency at a statistically significant level $(\kappa=0.41, \mathrm{p}=0.472)$.

This was mainly caused by the lack of a definite affirmative response from the first judge. He felt that the students generally didn't present a credible case for obtaining their goals with the exception of $3 \%$ who could be thought to have been successful. On the other hand, the second judge thought $8 \%$ of the students managed to present a credible case, and $15 \%$ of them might be considered able to do so. Despite this difference in their perception, it is important to note that both thought that a large majority of the students failed to present a credible case, further demonstrating the extent to which the students' pragmatic competence was limited. Considering all these components, the judges were asked whether or not their approach would be different from the students'. Despite their positive feelings about some students' performance in general, the judges stated that their approach would differ from that of the majority of the students $(85 \%$ and $97 \%)(\kappa=0.31, \mathrm{p}=0.001)$. When asked to explain the reason for this, they mainly stated that they would focus on ways to improve their assignment instead of focusing on the grade they were awarded. They also noted that they would avoid being demanding and aggressive in certain cases.

\section{Discussion}

The first research question aimed at identifying the components of the complaint speech act set employed by the participants. Results revealed that only about $66 \%$ of the participants produced a complaint, and a noticeable percentage $(40 \%)$ also opted for a criticism. Meanwhile, some students chose to employ both speech acts in their utterances. These students put the blame on the instructor and held him responsible for the perceived problem by criticizing him.

Their tendency to employ criticism as a way of resolving the issue resulted in their failure to meet certain felicity conditions. When students prefer to use criticism only, or go back and forth between criticism and complaint, they distort the accepted conventional procedure that would otherwise produce the intended conventional effect [4]. Another felicity condition stating that all the participants must execute the procedure correctly also does not seem to be met by these students. The criticisms uttered appear to discard the accepted sociolinguistic rules for a conversation between a student and a teacher.

The students' lack of sociolinguistic competence as language learners was also identified in previous research. For instance, Deveci found that Turkish learners opted for criticism and/or complaint when conversing with their teachers [11]. Similarly, Mayouf identified both speech acts in Iraqi students' discourse with their teachers [21].

Some participants' lack of sociolinguistic competence is further evidenced by their preference for demand as a solution. By demanding a solution from their instructor who has a higher social status than them, these students face the strong likelihood of their utterances becoming unhappy [4]. Demand as a solution has emerged in other research of a similar nature as well [11], [21].

The results of this also revealed that not all the components of the complaint speech act set were employed by the students. That is, an explanation of purpose was not provided by $20 \%$ of the students. Similarly, justification did not appear in $11 \%$ of the students' responses. Taken together, these show that the procedure for complaining was not fully executed by all participants, and therefore, this failure caused one of the felicity conditions to fail [4]. The result of this study regarding the reduced number of components also appeared in a previous study conducted with Sudanese students [31]. Although limited in number, these studies may indicate that Arab speakers regard complaining to someone of a higher status than themselves as highly facethreatening and therefore, end the discourse without completing all the expected components.

This may be because of a politeness strategy to avoid an imposition on their teachers, as Arabs have been thought to avoid confrontations that may potentially disturb their harmony with others [3]. This may be the possible reason that some of the participants in this study cut their conversation short by reducing the number of components in their speech act sets. Some of these students' conversations were significantly shorter than others, which may be further evidence of their tendency to be brief in forced confrontational situations.

The order in which the participants performed the components of the complaint speech act set also revealed some variation. Some students started the discourse with their instructor with a complaint and/or criticism, while others provided a justification for a complaint and/or criticism yet to be made. A solution was also seen as the first move in two of the students' responses.

These seem to have created some confusion about the reasons for their visits. Taken together, these data suggest that the students' were not completely clear about the order in which they should complete the target speech act set. This prevented them from meeting felicity condition A(i) requiring that "the procedure must be executed by all participants correctly" [4]. This, therefore, limited their pragmatic competence.

The second research question asked if gender or courses played a role in students' use of the complaint speech act set. The results on gender 
revealed that the female students were somewhat better at using the complaint speech act set. They produced the components of complaint, justification and request more often than their male counterparts. They, however, did not produce an explanation of purpose as frequently as the male students. The male students were also found to demand a solution more often than the female students (39\% vs $27.1 \%)$. There may be certain reasons for female students' tendency to use the complaint speech act set comparatively better. One of these may be related to the proficiency test the students took prior to their freshman studies. It appears that more of the female students took IELTS to be eligible for their studies. Various studies have investigated IELTS and TOEFL as predictors of readiness for academic contexts. For instance, Hill, Storch, and Lynch, (2000) compared the language proficiency scores from these examinations against students' Grade Point Averages (GPAs). They found a moderately strong correlation between IELTS scores and GPAs, but a relatively weak correlation between TOEFL and GPAs.

The respondents who had IELTS scores in our study may have also been better prepared for their academic studies. In addition, most of the male students in this study took paper-based TOEFL which didn't require a speaking module. IELTS, on the other hand, includes a compulsory speaking module. Evaluation of speaking competence in this exam includes 'evidence of communicative strategies' which would encourage test-takers to improve their communicative competence [30]. Further, the conversational nature of the speaking component of IELTS gives test-takers the opportunity to use communicative and interactive skills, which may be another reason that female students' behavior patterns in this study differed [8].

Gender differences in the frequency of complaints and the nature of complaints have been the topic of previous research as well. Wolfe and Powell found that both genders produced equivalent numbers of complaints; however, their reasons for complaining differed, and the female participants of the study used complaints to request an action indirectly [34]. The males, on the other hand, used complaints as a way of making themselves seem superior to the hearer. Basow and Rubenfeld also found that males tend to be more assertive and power hungry, whereas females were more likely to be tentative and polite in situations with conflict [7]. The finding in this research regarding male students' greater tendency to voice a criticism and demand a solution may also indicate males' orientation towards superiority.

This study also aimed at identifying any differences between COMM101 and COMM151 courses regarding students' use of the complaint speech act. Having had comparatively longer exposure to English, the COMM151 students were expected to produce a complaint more often. Surprisingly, however, COMM101 students resorted to this act more often than those in COMM151. However, COMM101 students also employed criticism and demand more often, making them less effective than COMM151 students. Combined with their more frequent usage of an explanation of purpose and a justification for their case, COMM151 students appeared to be comparatively more skilled in using the expected speech act set. However, it is important to note that almost $30 \%$ of the students still had sociolinguistically inappropriate tendencies such as issuing a demand.

The more frequent inefficiencies in COMM101 students' performance could be due to their limited experience in communication with their teachers about an unfair situation, particularly in a foreign language. Some of these students were direct entries without any experience at the English preparatory program of the university while COMM151 students had studied for at least one term as freshmen. Thus, their prior experience in their university courses may have prepared them better for how to converse with instructors about course-related matters.

Another focus of this study was the linguistic features of the complaint speech act set produced by the participants. The most noteworthy result related to this was the occurrence of mitigators in all of the students' utterances. Common examples included 'just' and 'maybe.' This helped them soften their complaints, as a politeness strategy helping the speakers to sustain face [19].

The students' tendency to mitigate their complaints could very often also have been caused by their desire to be cautious when conversing in a foreign language, believing "what is considered polite in their mother tongue could be rude in the target language context" [33]. The use of mitigators by Arabic speakers has also been argued to be influenced by their Islamic identity and the language itself which encourages Arabic speakers to use more politeness strategies by emphasizing solidarity and using mitigation more frequently compared to native speakers of English [2], [22]. Despite this, it is important to note the comparatively lower number of other linguistic features. For instance, questions were utilized only half as frequently as mitigators. On the other hand, the students depersonalized the problem thirty-two times. Also, only fifteen instances of the personal pronoun 'we', and thirteen instances of acceptance of partial responsibility of the problem occurred.

This shows that the students depended heavily on mitigation in putting their complaint to their instructor. This mitigation mainly included lexical items such as 'a little bit' and 'just' used in linguistically correct ways. However, good use of lexical, syntactic and semantic elements of the target 
language may not necessarily be accompanied by the sociolinguistic competence required for appropriate application of linguistic knowledge [25]. Together, the data in this research indicate a gap in students' effectiveness with the expected complaint speech act set. The students' reluctance to use a wider range of linguistic features likely resulted in their preferences for the speech act of criticism, which encourages the speaker to use the second person pronoun 'you,' thus, holding the hearer responsible for the problem faced [23]. Given the social distance between a university professor and a student, such an approach may easily create tension between the speaker and hearer.

The abovementioned factors may lead students to be deemed sociolinguistically inefficient users of the target language. In fact, this is evidenced by the acceptability judgments made by the judges in this study. They found many students pushy, and only respectful to a certain extent. Overall, they stated that their approach would be different from that of the students and would observe the power relationship with a professor more carefully. In their role as faculty to these students as well as native/proficient users of English language, the judges' evaluation is significant since it helps determine whether or not learners have performed the expected speech act appropriately [23].

\section{Conclusions and future directions}

University students' interaction with their instructors may pose certain challenges, especially in cases where they would like to perform the facethreatening act of a complaint, as was found to be the case in this study. Such a challenge can be even more formidable for students pursuing their studies in a foreign language. This may be particularly true for those who have not been exposed to the sociolinguistic aspects of the language in which they must converse with their instructors.

Their failures to perform the target speech act may therefore come across as offensive. When interacting with them, it is important that instructors be informed about students' backgrounds and the potential problems from which they may suffer. This would allow for more understanding on the part of instructors. At the same time, however, students would benefit from relevant guidance from their instructor. Ideally, content and language instructors would collaborate to create an intervention plan. It would also be beneficial for language instructors to focus more on face-threatening speech acts like complaints and refusals. These aspects of languages can easily be overlooked at the expense of grammar teaching.

This study had certain limitations in terms of data collection. First, how the complaint speech act is realized in students' L1 was not considered. Future research could consider how such speech acts are performed in students' L1, which could identify any negative and/or positive pragmatic transfer students may make. Raising students' awareness about the differences and similarities between L1 and L2 could help them perform speech acts more effectively. Second, this research used a role-play as a datagathering tool, the inauthentic nature of which may have had an impact on the data collected. Future researchers could replicate this study by collecting naturally- occurring data.

\section{References}

[1] Akinci, S. (1999). An Analysis of Complaints in Terms of Politeness in Turkish (Unpublished master's thesis). Hacettepe University, Ankara, Turkey.

[2] Al-Ali, M. and Alawneh, R. (2010). Linguistic mitigating devices in American and Jordanian students' requests. Intercultural Pragmatics, 7(2), 311-339.

[3] Al-Omari, J. (2008). Understanding Arab culture: a practical cross-cultural guide to working in the Arab world. Oxford: How To Books.

[4] Austin, J. L. (1962). How to Do Things with Words. Oxford: Oxford University Press.

[5] Azarmi, A. \& Behnam, B. (2012). The pragmatic knowledge of Iranian EFL learners in using face keeping strategies in reaction to complaints at two different levels. English Language Teaching, 5(2). 78-92.

[6] Boxer, D. (1993). Complaints as positive strategies: what the learner needs to know. TESOL Quarterly, 27(2), 277-299.

[7] Basow, S. A., \& Rubenfeld, K. (2003). Troubles talk: effects of gender and gender typing. Sex Roles, 48(3/4), 183-187.

[8] Brown, A. (2000). An investigation of the rating process in the IELTS oral interview. International Language Testing System Research Reports, 3, IELTS Australia, Canberra.

[9] Canale, M. \& Swain, M. (1980). Theoretical bases of communicative approaches to second language teaching and testing. Applied Linguistics, 1, 1-47.

[10] Cohen, A. D. (1996). Investigating the production of speech act sets. In S.M. Gass \& J. Neu (Eds.), Speech acts across cultures: Challenges to communication in a second language (pp. 21-43). Berlin: Mouton de Gruyter.

[11] Deveci, T. (2010). The use of complaints in the interlanguage of Turkish EFL learners, Colombian Applied Linguistics Journal, 12(2), 25-42.

[12] Ellis, R. (1994). The Study of Second Language Acquisition. Oxford: Oxford University Press 
[13] Fatmasari, D. R. (2015). Complaint strategy of EFL learners from the perspective of discourse completion task: A Case Study of Students of English Department Universitas Brawijaya (Unpublished master's thesis). Universitas Brawijaya, Indonasia.

[14] Hill, K., Storch, N. \& Lynch, B. (2000). A comparison of IELTS and TOEFL as predictors of academic success. International Language Testing System Research Reports, 3, IELTS Australia, Canberra.

[15] Hussein, J. Q. \& Al-Mofti, K. W. H. (2014). The speech act of complaint: A contrastive study of Iraqi and Chinese EFL learners of English. Anbar University Journal of Language and Literature, 13, $65-81$.

[16] Hymes, D. (1972). On communicative competence. In J. B. Pride \& J. Holmes (Eds.), Sociolinguistics, 269-293, Harmondsworth, England: Penguin Books.

[17] Kasper, G. (1992). Pragmatic transfer. Second Language Research, 8:3, 203-231.

[18] Levinson, S. C. (1989). Pragmatics. Cambridge: Cambridge University Press

[19] Lim, B. S. (2012). Transfer of politeness strategies: Some preliminary findings. In E.L. Low \& A. Hashim (Eds.), English in Southeast Asia: Features, policy and language in use (pp. 343-345). Amsterdam/Pheladephia: John Benjamins Publishing Company.

[21] Mayouf, H. H. (2013). The speech acts of complaint as realized by Iraqi Arabic speakers. Journal of Human Sciences, 1(14), 362-381.

[22] Muhammed, B. A. (2012). A contrastive pragmasociolinguistic study of etiquette teachings in English Christian and Arabic Islamic texts. (Unpublished doctoral dissertation). University of Baghdad, Baghdad.

[23] Murphy, B. \&. Neu, J. (1996). My grade's too low: the speech act set of complaining. In S. M. Gass \& J. Neu (Eds.), Speech Acts across Cultures: Challenges to Communication in Second Language, 191-216, Berlin: Mouton de Gruyter.

[24] Olshtain, E. \& Weinbach, L. (1993). Interlanguage features of the speech act of complaining. In G. Kasper \& S. Blum-Kulka (Eds.), Interlanguage Pragmatics, 108-122, New York, Oxford: Oxford University Press.

[25] Piotrowska, M. (1987). An investigation into the sociolinguistic competence of Hong Kong University students with specific reference to making complaints (Doctoral dissertation). University of Hong Kong, Hong Kong.

[26] Sauer, M. (2000). Complaints: A cross-cultural study of pragmatic strategies and

linguistic forms. Paper presented at AAAL Conference, Vancouver, Canada.

[27] Sasaki, M. (1998). Investigating EFL students' production of speech acts: a comparison of production tasks and role plays. Journal of Pragmatics, 30, 457-484.
[28] Searle, J. R. (1990). Speech Acts: An Essay in the Philosophy of Language. Cambridge: Cambridge University Press.

[29] Tabatabaei, S. (2015). Realization of complaint strategies by English and Persian native speakers, MJAL, 7(1), 123-145.

[30] UCLES. (1999). University of Cambridge Local Examination Syndicate, The British Council, and IDP Education Australia, Cambridge.

[31] Umar, A. M. A. T. (2006). The speech act of complaint as realized by advanced Sudanese learners of English. Umm Al-Qura University Journal of Educational, Social Sciences and Humanities, 18(2), 9-40.

[32] Weir, C. J. (1990). Communicate Language Testing. New York: Prentice Hall.

[33] Wijayanto, A. Laila, M. Prasetyarini, A. \& Susiati, S. (2013). Politeness in interlanguage pragmatics of complaints by Indonesian learners of English. English Language Teaching, 6(10), 188-201.

[34] Wolfe, J. \& Powell, E. (2006). Gender and expression of dissatisfaction: a study of complaining in mixedgendered student work groups. Women and Language, 29(2), 13-21.

[35] Yule, G. (1999). Pragmatics. Oxford: Oxford University Press.

[36] Zegarac, V. \& Pennington, C. (2000). Pragmatic transfer in intercultural communication, In H. S. Oatey (Ed.), Interculturally Speaking, 165-190, London: Continuum. 